\title{
Genetic variability and correlation analysis in hybrids of mulberry silkworm, Bombyx mori L. for egg characters
}

\author{
Md. Kamrul Ahsan and S. M. Rahman
}

Department of Zoology, University of Rajshahi, Rajshahi-6205, Rajshahi.

\begin{abstract}
The genotypic variability and correlation coefficients were studied in thirty five hybrid populations for five egg characters. Variations among genotypes were highly significant $(\mathrm{P}<0.001)$. Phenotypic coefficient of variation was higher than genotypic coefficient of variation for all the characters. Of them unfertilized and dead egg percentage showed highest difference between genotypic and phenotypic coefficient of variation suggesting most influence of environment on these characters. Majority of the characters showed high heritability except hatching percentage. Furthermore total number of egg laying per female showed high genetic advance together with high heritability, which indicates the importance of additive gene effect of this character. The genotypic correlations were higher than phenotypic correlation for majority of the characters under study except DEP Vs TEL and DEP Vs UEP. These low phenotypic correlations could be due to a modifying effect of environment and the association of characters at genotypic level. Hatching percentage, blue egg percentage and unfertilized egg percentage showed both positive and negative significant correlation to each other. Therefore, proper attention should be given to these characters specially total number of egg laid by female and hatching percentage in selection programme for genetic gain in Bombyx. mori.
\end{abstract}

Key words: Genetic variability, correlation, B. mori.

\section{Introduction}

Genetic variability is a prerequisite for an effective selection of any economically important plant and animal species, and a critical survey of genetic variability is essential aiming at developing high yielding varieties (Akanda et al., 1998). In silkworm breeding numerous traits are considered as important for improving them to increase the profit of silk producers and other sections of sericulture industry. Reproductive traits are considered important for egg producers. A great diversity of polyvoltine silkworm Bombyx mori L. must exist globally, considering the fact that many number of silkworm breeds are evolved by selection or cross breeding and also some of the tropical countries allowed individual farmers to produce silkworm eggs (Kumaresan et al., 2007)

Yield is the multiplicative end product of many factors which jointly or singly influence it. Grafius (1959) and House et al. (1958) are also of the opinions that yield is not an independent character, rather it results from the multiplicative interaction between various yield components. The selection of best genotypes depends on a number of characters. Therefore, a clear understanding and knowledge of association and contribution of various yield components is essential for any selection programme aimed at yield improvement.

Hence, the present study was undertaken to estimate the genetic variation for five important egg characters and correlations among them at phenotypic and genotypic levels for designing suitable breeding programmes.

\section{Materials and Methods}

The materials for this experiment of thirty five $F_{1}$ hybrids which were produced by using eighteen bi and multivoltine varieties of silkworm, B. mori. These parents were obtained from the Germplasm Bank maintained at the Bangladesh Sericulture Research and Training Institute (BSRTI), Rajshahi. The crosses were made to produce $35 \mathrm{~F}_{1}$ hybrids according to the following schedule:

\begin{tabular}{|c|c|c|c|}
\hline 1. BSR-3(M) $\times$ HTHRB-3 & 2. BSRTI-1×HTHRB-3 & 3. BSRTI-3×HTHRB-3 & 4. BSRTI-4×HTHRB-3 \\
\hline 5. BSRTI-5×HTHRB-3 & 6. BSR-3(M)×FT-B & 7. BSRTI-1×FT-B & 8. BSRTI-3×FT-B \\
\hline 9. BSRTI-4×FT-B & 10. BSRTI-5×FT-B & 11.HTHRB-3×BSR-3(M) & 12. HTHRB-3×BSRTI-1 \\
\hline 13. HTHRB-3×BSRTI-3 & 14. HTHRB-3×BSRTI-4 & 15. HTHRB-3×BSRTI-5 & 16. FT-B×BSR-3(M) \\
\hline 17. FT-B×BSRTI-1 & 18. FT-B $\times$ BSRTI-3 & 19. FT-B×BSRTI-4 & 20. FT-B $\times$ BSRTI-5 \\
\hline 21. 95/10×CCY-1 & 22. 95/10×CCY -3 & 23. 95/10×CCY-4 & 24. $95 / 14 \times \mathrm{CCY}-1$ \\
\hline 25. 95/14×CCY-2 & 26. 95/22×CCY-1 & 27. CCY $-1 \times \mathrm{CCY}-3$ & 28 CCY-1×Ziangsu-P \\
\hline 29. BV-M×CCY-2 & 30. CCY-2×Dong-P & 31. $\mathrm{S}_{98} \times \mathrm{CCY}-3$ & 32. $\mathrm{S}_{98} \times \mathrm{CCY}-4$ \\
\hline 33. $\mathrm{BV}-\mathrm{M} \times \mathrm{S}_{98}$ & 34. $\mathrm{S}_{98} \times$ Dong-P & 35. $\mathrm{S}_{98} \times$ Ziangsu-P & \\
\hline
\end{tabular}


The eggs of $F_{1}$ hybrids were brushed (3dfls for each genotype) in a randomized design with three replications each. The rearing was conducted in the rearing house No. 2 of the BSRTI, Rajshahi. Scientific technology of silkworm rearing was followed according to Krishnaswami (1978) and Rahman (1983). Data recorded for this study were: total number of eggs laid per female (TEL), hatching percentage (HP), blue egg percentage (BEP), unfertilized egg percentage (UEP) and dead egg percentage (DEP). The collected data were analyzed successively for estimating genetic variability, heritability and genetic advance according to the formula described by Burton \& De Vane (1953), Burton (1952), Hanson et al. (1956), Lush (1949) and Johnson et al. (1955). The phenotypic and genotypic correlations were calculated according to Al-Jibour et al. (1958). The formula was as follows:

$$
r\left(x_{1} x_{2}\right)=\frac{\operatorname{COV}\left(x_{1} x_{2}\right)}{\sqrt{V\left(x_{1}\right) V\left(x_{2}\right)}}
$$

\section{Results and Discussion}

Estimates of different statistics of overall range, mean with standard error and component of variations for different characters are presented in Table 1 . The major part of the total variation in the present study was contributed by the genotypic components in all the characters. The mean square estimates for all the characters were also shown in Table 1. The data in the table showed that there are highly significant differences among the genotypes for all the characters studied. Varietal differences with respect to egg, larval and cocoon characters in B. mori have been reported by Ahsan et al. (2000). Similar results on varietal diversity have also been substantiated by the findings of Sidhu et al. (1969), Govindan et al. (1987), Reza et al. (1993), Reza \& Rahman (1996) and Ahsan et. al. (1999).

The genetic parameters based on the analysis of variance for all the characters studied estimated, are presented in Table 2. Dead egg percentage, blue egg percentage, unfertilized egg percentage and total egg laid by female showed very high heritability together with high phenotypic (CVp) and genotypic (CVg) coefficient of variability. The estimates of genetic advance expressed as percentage of mean showed a wide range from 1.324 for HP to 147.769 for DEP.
Total number of eggs laid per female (TEL) expressed the highest genetic advance together with high heritability. It indicated the importance of additive gene effects of these characters (Panse, 1957; Rahman, 1984; Reza et al., 1993). It also indicated a wide rage of genetic diversity which could be used in a breeding programme and phenotypic selections of these characters would be effective. Mirhosseini et al. (2005) estimated higher heritability of cocoon weight and cocoon shell weight than that of cocoon shell ratio. Singh et al. (1994) also showed maximum heritability in SSW (80.20\%) followed by pupal weight with high heritability. Rao (1997) reported that the characters such as, single shell weight (in bivoltine) and single cocoon weight, single shell weight and filament length (in multivoltine) showed high heritability with high genetic advance.

High heritability does not always give high genetic advance as was indicated by Johnson et al. (1955). High heritability but relatively low genetic advance were observed for the characters such as BEP, UEP and DEP. It suggested limited scope for manipulation of these characters. These could be due to non-additive gene action which includes dominance and epitasis (Liang \& Walter, 1968). In such situations, progeny testing and recurrent selection might be helpful to improve these traits (Rahman, 1984; Govindan, et. al. 1987; Rao, 1997; Ahsan et al. 1999, 2000). Sen et al. (1995) had shown high heritability and moderate genetic advance for larval weight, single cocoon weight in multivoltine silkworms. Reza et. al. (1993) and Reza \& Rahman (1996) found a non-additive component of genetic variation as an important feature of some larval and cocoon characters in B. mori.

Phenotypic $\left(\mathrm{r}_{\mathrm{p}}\right)$ and genotypic $\left(\mathrm{r}_{\mathrm{g}}\right)$ correlations between all pairs of characters studied in this investigation analysed are shown in Table 3 . In general, genotypic correlation coefficients $\left(r_{g}\right)$ were greater in magnitude compared to those of phenotypic correlations $\left(r_{p}\right)$. These low phenotypic correlations could be due to a modifying effect of environments of the association of characters at genotypic level (Rahman, 1984).

Table 1. Range, mean with SE, mean square and components of variance of different characters of hybrids of silkworm, B. mori.

\begin{tabular}{l|l|r|r|r|r|r|r}
\hline Characters & \multicolumn{1}{|c|}{ Range } & Mean & SE & MS & P & G & E \\
\hline TEL & $286-631$ & 489.37 & 4.03 & $14349.27^{* * *}$ & 4799.36 & 4774.95 & 24.41 \\
\hline HP & $61.12-86.81$ & 79.68 & 2.20 & $51.522^{* * *}$ & 22.01 & 14.76 & 7.25 \\
\hline BEP & $1.28-22.95$ & 6.40 & 0.16 & $37.871^{* * *}$ & 12.65 & 12.61 & 0.04 \\
\hline UEP & $0-11.83$ & 5.08 & 0.30 & $15.752^{* * *}$ & 5.34 & 5.21 & 0.14 \\
\hline DEP & $0-9.89$ & 3.28 & 0.36 & $17.417 * * *$ & 5.94 & 5.74 & 0.20 \\
\hline
\end{tabular}

*** Significant at $0.1 \%$ level, $\mathrm{P}$ = Phenotypic variance, $\mathrm{G}=$ Genotypic variance, $\mathrm{E}=$ Environmental variance. 
Similar results were also reported by Sen et al. (1976); Siddiqui et al. (1992) in Antheraea mylitta, and Ahsan and Rahman (1997, 2000) in B. mori. Total number of eggs laid per female showed insignificant correlations with most of the characters except UEP $(\mathrm{P}<0.01)$ both at phenotypic and genotypic levels. Hatching percentage, BEP and UEP showed both positive and negative significant correlation to each other. Shamachary et al. (1980) found significant positive correlations of mature larval weight with cocoon weight and shell weight in B. mori. Mistri \& Jayaswal (1992) found high significant positive correlation between shell weight and cocoon weight; shell weight and pupal weight in both sexes in B. mori. Singh et al. (1994) reported the same results between shell weight and fecundity. Chatterjee \& Pradeep (2003) investigated the relationship between yield potential and molecular markers in silkworm.

Table 2. Phenotypic (CVp), genotypic (CVg), and environmental (CVe) coefficient of variation, heritability ( $\left.\mathrm{h}^{2}\right)$, genetic advance (GA) and genetic advance as percentage of mean (GA\%) for different characters of hybrids of silkworm, B. mori L.

\begin{tabular}{l|c|c|c|c|r|r}
\hline Characters & CVp & CVg & CVe & $\mathbf{h}^{2}$ & GA & GA\% \\
\hline TEL & 14.156 & 14.120 & 1.010 & 99.491 & 141.986 & 29.014 \\
\hline HP & 0.959 & 0.785 & 0.550 & 67.067 & 6.481 & 1.324 \\
\hline BEP & 55.609 & 55.528 & 3.009 & 99.707 & 7.305 & 114.219 \\
\hline UEP & 45.513 & 44.936 & 7.287 & 97.436 & 4.639 & 91.353 \\
\hline DEP & 74.218 & 72.965 & 13.582 & 96.651 & 4.852 & 147.769 \\
\hline
\end{tabular}

Table 3. Phenotypic $\left(r_{p}\right)$ and genotypic $\left(r_{g}\right)$ correlation coefficients between all pairs of characters of hybrids of silkworm, B. mori L.

\begin{tabular}{c|c|c|c|c|c}
\hline Variables & & TEL & HP & BEP & UEP \\
\hline \multirow{2}{*}{ HP } & $\mathrm{r}_{\mathrm{p}}$ & 0.106 & & & \\
\cline { 2 - 6 } & $\mathrm{r}_{\mathrm{g}}$ & 0.133 & & & \\
\hline \multirow{2}{*}{ BEP } & $\mathrm{r}_{\mathrm{p}}$ & -0.058 & $-0.763^{* * *}$ & & \\
\cline { 2 - 6 } & $\mathrm{r}_{\mathrm{g}}$ & -0.058 & $-0.935^{* * *}$ & & \\
\hline \multirow{2}{*}{ UEP } & $\mathrm{r}_{\mathrm{p}}$ & $-0.435^{* *}$ & $-0.497^{* *}$ & $0.449^{* *}$ & \\
\cline { 2 - 6 } & $\mathrm{r}_{\mathrm{g}}$ & $-.441^{* *}$ & $-0.626^{* * *}$ & $0.455^{* *}$ & -0.015 \\
\hline \multirow{2}{*}{$\mathrm{DEP}$} & $\mathrm{r}_{\mathrm{p}}$ & 0.069 & $-0.436^{* *}$ & $0.365^{*}$ & -0.012 \\
\cline { 2 - 6 } & $\mathrm{r}_{\mathrm{g}}$ & 0.068 & $-0.533^{* * *}$ & $0.369^{*}$ & \\
\hline
\end{tabular}

From the study of genetic parameters and characters association, it could be said that these characters had the inherent association to each other specially the characters, total number of egg laid by female and hatching percentage and thus merit prime importance in selection with programmes for genetic gain in B. mori.

\section{Reference}

Ahsan, M.K. \& Rahman, S.M. 1997. Correlation and path coefficient analysis in indigenous varieties of silkworm, B. mori L. Univ. j. zool. Rajshahi Univ. 16: 35-38.

Ahsan, M.K. \& Rahman, S.M. 2000. Correlation and path coefficient analysis of some yield contributing characters in hybrids of mulberry silkworm, Bombyx mori L. J. Asiat.Soc. Bangladesh, Sci. 26(2): 197-202.

Ahsan, M.K., Rahman, S.M. \& Ali, I.A. 1999. Inheritance of some quantitative traits in fifteen indigenous varieties of silkworm, Bombyx mori L. Univ. j. zool. Rajshahi Univ. 18: $79-83$.

Ahsan, M.K., Rahman, S.M. \& Ali, I.A. 2000. Variability of some quantitative traits in the hybrids of silkworm, Bombyx mori L. Univ. j. zool. Rajshahi Univ. 19: 20-24.
Akanda, M. A. L., Alam, M. S. \& Uddin, M. M. 1998. Genetic variability, correlation and path analysis in composite maize. Bangladesh J. Agril. Res. 23 (1): 107-113.

Al-Jibour, H.A., Miller, P.A. \& Robinson, H.P. 1958. Genotypic and environmental variances in Upland cotton cross of interspecific origin. Agron. J. 50: 633-637.

Burton, G.W. 1952. Quantitative inheritance in grass. Proc. $6^{\text {th }}$ Inter. Grassland Cong. 1: 277-283.

Burton, G.W. \& De Vane, E.H. 1953. Estimating heritability in tall fescue (Fescuta arundinacae) from replicated clonal meteriasa. Agron. J. 45: 579-604.

Chatterjee, S. N. \& Pradeep, A. R. 2003. Molecular markers (RAPD) associated with growth, yield, and origin of the silkworm, Bombyx mori L. in India Russian Journal of Genetics. 39(12): 1365-1377.

Govindan, R., Magadum, S. B. \& Satenahalli, S. B. 1987. Breeding with some polyvoltine and bivoltine strains of the silkworm, Bombyx mori L. Sericologia. 24: 597-604.

Grafius, J. E. 1959. Heterosis in barley. Agron. J. 51: 551-554. 
Hanson, C. H., Robinson, H. F. \& Comstock, R. E. 1956. Biometrical studies of yield in segregation populations of Korean lespedeza. Agron. J. 48: 268-272.

House, R. N. H., Thompson, J. B. \& Devalle Ribairo, M. A. M. 1958. Studies on the breeding of self pollinated cereals. 2 . The use of diallel cross analysis in yield prediction. Euphytica. 7: 147-169.

Johnson, H. W., Robinson, H. F. \& Comstock, R. E. 1955. Estimates of genetic and environmental variability in soyabean. Agron. J. 47: 314-318.

Krishnaswami, S. 1978. New Technology of silkworm rearing. Central Silk Board, India. 23pp.

Kumaresan, P., Sinha, R. K. \& Urs, S. R. 2007. An analysis of genetic variation and divergence in Indian tropical polyvoltine silkworm, Bombyx mori L. genotypes Caspian J. Env. Sci. 5(1): 11-17.

Liang, G. H. L. \& Walter, T. L. 1968. Heritability estimates and gene effects for agronomic traits in grain sorghum. Crop Sci. 8(1): 77-80.

Lush, J. L. 1949. Heritability of quantitative characters in farm animals. Heriditas (suppl.). 35: 256-261.

Mirhosseini, S. Z., Ghanipoor, M., Shadparvar, A. \& Etebari, K. 2005. Selection indices for cocoon traits in six commercial silkworm, (Bombyx mori). lines. The Philippine agricultural Scientist. 88(3): 328-336.

Mistri, P. K. \& Jayaswal, K. P. 1992. Studies on phenotypic correlations between some economic traits of silkworm, Bombyx mori L. Bull. Seric. Res. 3: 26-29.

Panse, V. G. 1957. Genetics of quantitative characters in relation of plant breeding. Indian J. Genet. 17: 318-324.

Rahman, S. M. 1983. Technology of mulberry silkworm rearing suitable for the climatic condition in Bangladesh. Reshom 1: 71-79.

Rahman, S. M. 1984. Studies on the genetic improvement of eri silkworm, Philosamia ricini. Boisd of Bangladesh. Ph.D thesis, Department of Zoology, Rajshahi University. 419pp.
Rao, P. R. T. 1997. Genetic architecture and gene action in Bombyx mori L. Ph.D thesis, Department of Zoology, University of North Bengal, Darjeeling-734430, India. 191pp.

Reza, A. M. S., Rahman, M. S. \& Rahman, S. M. 1993. Studies on the variation of some larval traits in different breeds of silkworm, Bombyx mori L. Univ. j. zool. Rajshahi Univ. 12: 21-24.

Reza, A. M. S. \& Rahman, S. M. 1996. The genetic variability, heritability and genetic advance in silkworm, Bombyx mori L. Bangladesh J. Agri.21: 1-6.

Sen, S. K., Sengupta, A. K., Das, M. G. \& Jolly, M. S. 1976. Studies on genetic variability, correlation, pathcoefficient analysis and discriminant function in Antheraea mylitta D. Indian J. Seric. 15: 9-14.

Sen, S. K., Das, S. K., Rao, P. R. T., Ghosh, B., Das, N. K., Chattopadhyay, S., Roy, G. S. \& Sinha, S. S. 1995. Studies on some important genetic parameters in silkworm, Bombyx mori L. Indian J. Genet. 55(3): 238242.

Shamachary, M., Samson, V. \& Krishnaswami, S. 1980. Some useful correlation studies of silkworm and its products such as cocoon, pupa, shell and egg weight. Indian J. Seric. 19: 4-8.

Siddiqui, A. A., Sinha, M., Kumar, A., Bajpayi, C. M. \& Sinha, S. S. 1992. Selection of better genotypes through path-coefficient analysis in segregating generation of Antheraea mylitta D. Sericologia. 32(2): 239-245.

Sidhu, N. S., Tikoo, B. L., Singh, K. \& Pillai, S. V. 1969. New hybrids for commercial crops for multivoltine gerions. Silkworm Inf. Bull. 1: 18-25.

Singh, T. Chandrashekharaiah \& Samwo, M. V. 1994. Selection strategies in relation to correlation and heritability in the silkworm, Bombyx mori L. Bull. Seric. Res. 5: 37-41.

Manuscript received on 09.06.2008, accepted on 06.09.2008 